in a few minutes, and healed in six hours. In this way infection by wound is practically impossible. In thirty-six hours all traces of the operation should be gone. In about thirty-six hours more, if the vaccine is to "work," a "mosquito bite" appears over the site of each wound; that gradually increases into a little vesicle, which in turn is surrounded by a zone of redness, and if typical, on the eighth day the two resemble a "pearl on a rose leaf," as Jenner described the vesicle of this time at court. On the ninth day suppuration occurs, constitutional symptoms begin to appear, with increased local redness and swelling; by the twelfth day these diminish, the areola begins to fade, the soreness decreases, and the vesicle discolors and dries up. When the wound is entirely healed the crust falls off, leaving the characteristic scar. Of course the operator has clean hands and takes the same precautions as in other important surgery.

Using the simple method above described, I have never had any serious "accident" and never saw an instance in which there was any evidence of other infectious disease having entered the body with the vaccine. I have seen a few cases in which a broken vesicle had opened the way for septic poison and bad results had followed, but none in which such results was not the direct consequence of injury. Any instance in which septicemia in any form occurred, has been, in my experience, of this chara ster.

These facts are so because, with us, the same care and precautions have been taken in using as in collecting vaccine. Until medical men will insist upon the same rules and use them in their own practice, the present professional and popular distrust of vaccination will not only continue, but increase, as it ought to do.

It is proper that I should state the method by which I have repeatedly been able to overcome opposition to vacination in the presence of smallpox. Argument in the ordinary sense is useless, nor does it seem to be worth while to spend breath and patience in that way. I state my personal confidence in the necessity of the operation, and prove my faith in the vaccine by offering to be the first to submit to its use. Such evidence has never failed to persuade even the most ignorant and obstinate, and has inspired a confidence which has amply repaid the slight trouble involved.

It is well not to forget that the secret of Jenner's discovery was really found in the experience of the laboring class, who most need its beneficent modification to-day.

There are many physicians and health officers who, appreciating existing difficulties, are urging compulsory legislation and a fine of parents for neglect of raccination of children. I trust they have studied the history of such legislation and watched the effect in England where the compulsory law is openly violated to-day because of the opposition created by itself and by blundering attempts at its enforcement.

My experience has been large enough to enable me to have an opinion founded upon it, and I unhesitatingly declare for no other legislation than the power to isolate as for any other infectious disease. That is all we have in Minnesota, though the legislature has more than once been willing to go further if requested. The results of our present methods appear in our published experience of their use, in a steady reduction of smallpox prevalence from the beginning to date, though the disease has been epidemic more than once in adjoining States since it assumed the form of lim- ited endemics, and often what may be called "family outbreaks" in Minnesota.

If we can overcome prejudice fostered by controversies as to forms of vaccine, and the notorious accidents which have followed the use of commercial calf lymph at various times, there will be no difficulty in reëstablishing infant vaccindtion as a habitual custom again, and making a certificate of successful vaccination a necessary prerequisite to admission to all schools, on the demand of the people themselves.

It is fortunate that the claims of vaccine rest upon a long experience, both popular and medical, of their usefulness in actual service. It is not a laboratory product, and not comparable with antitoxin for diphtheria, for example, as it does not involve intricate artificial processes of production or use. It is a result of common experience in the dairy and the stable, carried to positive demonstration by Jenner in common experience too. Its value has been tested as no other agent for prevention of disease ever can be.

Its value is simply this, that its proper use has stayed the progress of a great plague. That use is one hundred years old to-day. Smallpox, a terror one hundred years ago, is to-day, because of vaccine, the most easily controlled of all infections diseases.

In a dark and secluded place near the great west doors of Gloucester cathedral stands a statue of Jenner. When I saw it in 1889 it was covered with dust and had every appearance of neglect. In the city of Gloucester, near where Jenner lived and made his discovery, and where I think he at one time practiced his profession, the anti-vaccination party have, within a few years, won what they call a victory, and deprived hundreds of children of the protection against smallpox, which, in that city, was peculiarly their birthright. Medical men and health officers warned the authorities that it was only a question of time when the plague would be upon them. It is there to-day, in the centennial year of the discovery of vaccine, and too late to prevent, but not too late to crush out the disease; vaccination is again in urgent demand and imperative use.

When the fight is over, the dead buried, the disabled and deformed provided for, the least that the people of Gloucester can do will be to punish those who have so grievously misled them, clean and beautify that statue of Jenner, add another grateful inscription to its base, sing a $\mathrm{Te}$ Deum, and publish their reconversion by terrible and needless experience to the belief that vaccination for the prevention and control of smallpox is the most clearly demonstrated fact in the history of the management of disease.

\section{THE DISCOVERY OF VACCINATION.}

Address delivered at the Centennial Celebration held at Atlanta, BY JEROME COCHRAN, M.D. MONTGOMERY, ALA.

Great is the name of Jenner. It marks an important historical epoch. Before Jenner, smallpox was king-king in the palace and in the hovel-king all the time and everywhere. In civilized Europe it claimed annually many hecatombs of human lives. After Jenner vaccination was king, and under the protection of its invulnerable armor men and women were enabled to walk in the midst of pestilence with impunity. Such and so great was this man's discovery. No wonder that his fame comes to us resound- 
ing down the corridors of time. No wonder that in the catalogue of great doctors he stands out in bold relief as one of the greatest. He has, perhaps, done more for the salvation of human lives than any other man that ever lived.

But a truce to panegyrics, and now to our problems.

Smallpox is the type of specific infectious diseases. It runs a definite course, can not be cut short by treatment, and one attack, in the immense majority of cases, protects the entire system against subsequent invasion. Nevertheless, second attacks are not unknown. I have myself seen one case of a patient who recovered from a first attack of confluent smallpox and afterwards died of a second attack a few years later.

Of the physical character of the smallpox poison very little is known, and I touch upon this point very briefly, because I believe it is to be treated of specially during this discussion by a distinguished bacteriologist. But we do know something about it. We know, to begin with, that it is organic and living, because it is endowed with the faculties of growth and reproduction; and we know that it is composed of semi-solid, colloidal particles, because living functions can not be manifested by gases and liquids.

The poison of smallpox being thus animate and particulate is generated exclusively in the bodies of men and women. It is probably thrown off from all the eliminating surfaces of the smallpox patients. It can be carried from place to place and from person to person, on the point of a lancet, in bedding and clothing, by cats and dogs, and perhaps by flies. It is doubtless carried through the air for short distances; but it is important to remember that it will not ordinarily cross a street unless it is carried by some human or animal agency. If it invades the premises of your next door neighbor you can close the windows on that side of the house and sleep in peace.

How the smallpox poison finds its way into the bodies of its victims is a question of curious interest. It is usually assumed that it is taken in the act of respiration, although we know that the vibrissæ of the nose strain out nearly all the bacteria of inspired air; and that the mucous membrane of the nose is highly antiseptic. I do not know that it has even been supposed to gain entrance by way of the mouth. I should be strongly tempted to believe that it is always introduced through some abrasion by some indirect process of inoculation, but for the fact that the symptoms of inoculated smallpox differ so widely from the symptoms of smallpox contracted in the usual way. At the point of inoculation in inoculated smallpox the papule can be discovered on the third day; the vesicle at the point of inoculation is fully developed on the fifth day, and the eruption over the body is in full bloom on the eighth day. In ordinary smallpox the usual period of incubation is twelve to fourteen days. So the theory of accidental inoculation will not hold good.

The smallpox poison is very easily destroyed. It is killed at a temperature below that of boiling water. It is killed by the fumes of sulphur. It soon disappears by exposure to sunshine and fresh air. In spite of all the books say to the contrary, it shows far less disposition to spread in warm weather than in cold weather. In our long southern summers on the Gulf coast it almost dies out, even when no effort is made to prevent its spread. It affects the negroes much more severely than it does the white people.
In passing throurh the body of the cow the virulence of smallpox is greatly modified, so that cowpox is a very much milder disease than smallpox. Vaccinia, the product in the human subject of inoculation by the virus of cowpox, is a mild disease, and affords protection against ordinary smallpox. This is the discovery of Jenner which we celebrate to-day, and furnishes us with an easy transition from problems in smallpox to problems in vaccination.

As of the virus of smallpox so of the virus of vaccinia; we know but little of its physical and vital. composition. For the same reasons as those mentioned in the discussion of the virus of smallpox we know that the active agent in the virus of vaccinia is a living colloidal, particulate organism. Ernst and Martin, of Boston, are reported to have found in vaccine lymph a micrococcus which can be separately obtained, and which when inoculated in calves and children will produce the characteristic vesical. I know nothing of the details of their research. The almost forgotten researches of Chauveau in 1865 to determine the infectious principle of vaccine lymph, are perhaps still of some value. He found vaccine lymph to be composed of a fluid part, in which were white blood corpuscles, and a number of granules many times smaller than the leucocytes. These constituents were separated by a process of diffusion and it was shown that on inoculation it was the granules and the granules alone that communicated vaccinia. Chauveau's conclusions seem to have received confirmation from similar experiments made by Ferdinand Cohn and Burdon-Sanderson. Cohn even asserted that those micrococci could be cultivated outside human and animal bodies.

Smallpox may be prevented from spreading by the intelligent interposition of isolation and disinfection. But of all the prophylactic measures which have ever been made use of against smallpox vaccination is by common consent the most important. When Jenner had succeeded in demonstrating his discovery, it was confidently predicted that the reign of smallpox would be speedily ended, and the world permanently freed from the immeasurable evils which during many centuries it had inflicted on the human family. Very vigorous efforts were employed by the medical profession to extend the practice of vaccination amongst the people generally; and in many, perhaps in most, European countries it has been made obligatory by express provision of law. The results have not been altogether in harmony with the anticipations of its advocates. It is true that the prevalence of smallpox has been greatly diminished; and it is true that the percentage of smallpox mortality to population has exhibited much lower averages since the introduction of vaccination than before; so that there can be no question that it has been the means of saving the lives of many thousands, I might perhaps safely say, of many millions of human beings. Saving so many lives I have said; I should have been more accurate if I had said, prolonged so many lives; for of course finally all of them have to die.

But notwithstanding all this, the dreadful malady which had been so confidently consigned to extermination, has still managed to maintain a tolerably vigorous existence among the nations. Now that the conditions of the problem are better understood we are obliged to conclude that the final extinction of smallpox will not be accomplished until our civilization obtains a much higher grade of development than any 
which it now presents, or which it is likely to reach for some centuries to come. The reason for this conclusion is easily found. It is not that our medical ancestors were greatly mistaken in their estimate of the protective value of vaccination; but that the experience of a century has shown that under existing circumstances it is practically impossible to secure the thorough vaccination of the whole population of cities and states.

And yet the prophylactic efficacy of vaccination has been and is now to some extent over-estimated, because a great many physicians do not sufficiently appreciate that in very many cases the temporary protection afforded by vaccination is not permanent, does not last for the remainder of life; and because so many vaccinations are inadequately done. A single small vaccine vesicle will protect for a time. But several vesicles or a cluster of vesicles will protect for a much longer time.

Then there are a considerable number of our fellow-citizens, who are very earnestly opposed to vaccination. It is true that in this opposition they are most unwise, but even in their folly they are entitled to considerate treatment. Only two or three weeks ago $I$ read in the Association Journal that there was then prevalent in Gloucester in England a sweeping epidemic of smallpox due to the resolute refusal of vaccination by an anti-vaccination league. And this in the very county in which Jenner pursued his investigations. Compulsory vaccination laws inevitably lead to anti-vaccination leagues.

I am myself opposed to compulsory vaccination laws. I think they trench too much on the liberty of the citizen, and beget a very troublesome opposition from many who would otherwise in case of danger submit to vaccination as a matter of course. I know the argument is that these anti-vaccination cranks imperil the health of communities. Sometimes they do; but communities can protect themselves by isolation and disinfection-in a word, by quarantine against the few dangerous persons who would hold out against vaccination in emergencies; and if any of my fellow-citizens insist on running the chances of dying from smallpox I would be the last man to deprive them of that privilege.

Much has been written as to the comparative merits of humanized and bovine vaccine. It is the fashion just now to prefer the bovine virus, and $I$ in practice follow the fashion. We do not have much smallpox in Alabama and consequently we do not need much vaccine. When we do need it it is convenient to order the bovine article, and we do so. But I am profoundly satisfied from a very large experience that the humanized virus, in the form of lymph or of crust, has equal prophylactic power, is equally safe from unfavorable complications, and is followed by a smaller percentage of bad arms. The enthusiasm for the bovine virus has been largely manufactured to order by the managers of vaccine farms. Jenner used the humanized virus, and Jenner's successors for two generations used the humanized virus. The common use of the bovine virus has grown up during the last thirty years.

The communication of syphilis along with the vaccine is the complication that has been specially dreaded. I know the famous cases related by Mr. Jonathan Hutchinson, and by Mr. Thomas Sinith. I know nothing about Mr. Smith, but I do know that Mr. Hutchinson was always seeing a lot of things that were not obvious to anybody else; and I remain very incredulous about vaccinal syphilis. In Mobile in 1874, some twelve thousand vaccinations were done with the humanized lymph, and I never heard of a case of vaccinal syphilis.

The vaccine vesicle is a living thing--a growth as much as cancer or tubercle is a growth, and the presumption is that in the process of growth it converts everything which it appropriates into its own nature, and this without regard to the soil in which it grows. Just as, for illustration, the poisonous night-shade, the delicious strawberry, and the medicinal poppy, may all grow side by side, out of the same soil, and be fed with the same food, and yet each remaining true to its own special nature, will produce its own characteristic fruit.

The location of the vesicle is among the epithelial elements of the derma. The epithelial cells take part in the growth of the vesicle, and it is through their agency that it becomes many chambered. The chambers are filled with transparent lymph. It never passes through a pustular stage. In about eight days it attains its full development, after which the lymph gradually concretes into a crust which is firm and tough and translucent like horn. The color is sometimes a light amber, sometimes a deep amber, sometimes a dark mahogany, and sometimes almost an ebony black, depending always on the color of the skin on which it grew. The darker the skin the darker the crust. The color is due to the pigment cells which remain entangled in the crust when it dries.

I hope I may be excused for speaking at so much length. Gentlemen, I thank you for your kind attention.

\section{CLINICAL MEMORANDA.}

Read before the Chicago Pathological Society, April 13, 1896. BY ARTHUR R. EDWARDS, M.D.

Professor Therapentics Northwestern University Medical School; Atteuding Pliysician Cook County Hospital ; Pathologist to Cook County, St. Luke's aud Wesley Hospitals.

I. CASE OF CIRRHOSIS OF LIVER WITH PRE-ASCITIC EDEMA OF LOWER EXTREMITIES.

J. A. N., a laborer, married, 43 years old, American; under observation from Jan. 25 to Feb. 6, 1895. By occupation he was an engineer. His affection began two weeks before entrance, with an initial chill, with pains over the entire body, in every joint and in the head. He had during this period suffered from hourly vomiting, and frequent diarrhea. The bowels had been usually constipated. Hiccough had troubled him excessively. His wife stated that the patient's illness began suddenly with involuntary evacuations from the bladder and rectum, accompanied by an enormous appetite and thirst. His left arm had been limp and painful for some time past. The lower extremities, together with the other parts, have grown emaciated till some six days since, when considerable anasarca about the legs and ankles developed. $\mathrm{He}$ had always lived in this State. He married a year ago. His wife noticed large veins in the legs, but had never seen any upon the abdomen.

Examination: Involuntary urinary and fecal evacuations existed with retention of urine, $4,100 \mathrm{c.cm}$. of urine being withdrawn at one time. The urine contained no albumin nor sugar, was neutral, sp. gr. $1013,2.3$ per cent. urea, no pus nor casts in the sediment. Respirations varied from 18 to 20 , the pulse 